\title{
Chemical warfare in the First World War: reflections 100 years later
}

\author{
Aswin Mangerich · Charlotte Esser
}

Received: 8 September 2014 / Accepted: 11 September 2014 / Published online: 23 September 2014

(C) Springer-Verlag Berlin Heidelberg 2014

This year marks the 100th anniversary of the beginning of the First World War (WWI), which brought disaster to countries during the years of 1914-1918 and was a historical turning point for Europe. More than 16 million people were killed during this war, and there are few cities and villages in Europe which have no monument to the memory of these deaths.

It was during WWI, when chemical warfare agents (CWA) were used as weapons of mass destruction for the first time (Szinicz 2005), and we think this anniversary is a challenge for reflection. By 1918, the main big powers of the war produced more than 125,000 tons of CWA and there were over one million casualties by chemical weapons with more than 90,000 being fatal. Many different chemicals were used and developed for the purpose of warfare, among them the lung toxicants, chlorine and phosgene (carbonyl dichloride), and the vesicant and blistering agent sulphur mustard (SM, 2,2-dichlorodiethylsulfide, also known as Yellow Cross, S-LOST, Yperite, or HD) (Fitzgerald 2008). Later years saw the addition of new chemicals, such as nerve agents sarin, tabun, and others, which represent the most toxic group of CWA so far. Moreover, new uses were employed for chemicals such as the defoliating Agent Orange in the Vietnam War, whose contaminating dioxins had adverse health effects on the population as well (Pitschmann 2014). Tabun and sulphur mustard were

\footnotetext{
A. Mangerich

Molecular Toxicology Group, Department of Biology, University

of Konstanz, Konstanz, Germany

e-mail: aswin.mangerich@uni-konstanz.de

C. Esser $(\square)$

IUF-Leibniz Research Institute for Environmental Medicine,

Auf'm Hennekamp 50, 40225 Düsseldorf, Germany

e-mail: charlotte.esser@uni-duesseldorf.de
}

released in the Iran-Iraq war (1980-1988), poisoning more than 100,000 persons (Gupta [Ed] 2009). Sarin was used in an attack in the currently ongoing Syrian Civilian War, and more than 1,400 people died in 2013 (Dolgin 2013).

The international community has outlawed CWA long ago. As early as 1899 , the Hague Declaration, followed by the Hague Convention of 1907, forbade the use of poisonous gas. The ban and prohibition was later also included in the Geneva protocol from 1925 and is now part of international humanitarian law. However, it took many more decades for the next step. The Convention on the Prohibition of the Development, Production, Stockpiling and Use of Chemical Weapons and their destruction (Chemical Weapons Convention, CWC) came into force only $1997 .^{1}$ It obliges the signatory states to destroy their chemical weapons, and according to the Organization for the Prohibition of Chemical Warfare (http://www.opc.org), which was awarded the Nobel Peace Prize in 2013, $83 \%$ of the world's declared approximate 72,000 tons of CWA have been destroyed by now. The convention has been signed by 190 states by now, but there remain six states that have not signed or ratified it. Nonetheless, although all parties to an armed conflict, whether states or nonstate actors, are bound by international humanitarian law, the potential use of CWA in asymmetric conflicts and terrorist attacks remains a predominant concern.

Why should all of this be of interest to toxicologists? This question goes hand in hand with the question if CWA still represent a current danger to societies in the world. Chemical weapons are relatively easy to synthesize and to deliver (Gupta [Ed] 2009). In Japan, in the 1990s, 19 people were killed and 6,000 were injured after sarin attacks

\footnotetext{
$\overline{1}$ http://www.opcw.org/chemical-weapons-convention/.
} 
of the Aum Shinrikyo sect (Yanagisawa et al. 2006). The threat of CWA is probably real. Toxicological research can increase our understanding of the complex toxicity profiles and mechanisms of action of CWA. There is also a need to improve diagnostic tools and therapeutic options. For instance, while some progress was made for an antidote against organophosphate-based nerve agents (Rodgers and Condurache 2010; Dolgin 2013), the situation for sulphur mustard is more disappointing. Indeed, even a century after its first use on the battlefield, there is still no effective antidote available (Thiermann et al. 2013).

A second area for research concerns the diagnosis and verification of CWA exposure, which is needed to decide on therapy. An example of successful forensic detection of CWA was given in Syria in 2013 when ultimate proof was provided by several OPCW-selected laboratories shortly after the alleged release of sarin (Enserink 2013). Reliable tests exist for only selected CWA (e.g. nerve agents, SM). As the analytical detection of poisons traditionally has been a central issue in toxicological research, modern toxicology is able to provide substantial expertise and tools to improve the detection and quantification of CWA in environmental and tissue samples (Maurer 2007; Black 2010).

Toxicological knowledge can help recognizing the risks associated with (new) chemicals and raising awareness for abuse. There are toxic chemicals that are so far not or only poorly regulated by the CWC. "Incapacitating", nonlethal agents, such as tear gas, are currently allowed under the CWC. The term nonlethal chemical weapon is problematic from a toxicologists point of view as such compounds can be nonlethal to some people but not to others, depending on gender, age, general health, and the actual exposure (Pitschmann 2014). A tragic example represents the Moscow theatre hostage crisis in 2002, when a mixture of opioids was used to overwhelm kidnappers and free the hostages, which caused the death of $15 \%$ of all people present in the theatre (Riches et al. 2012). There is a growing awareness that new toxicological findings on established and new chemical weapons need to be implemented into an updated version of the CWC (Sydnes 2013).

Finally, there is an issue of dual use potential of chemicals, i.e. a chemical can be used either to harm or to save lives. Modern scientific approaches, such as combinatorial chemistry or nanotechnology, harbour a big risk for the development of new chemical weapons (Pitschmann 2014). On the other hand, chemicals used to synthesize CWA can be used as common industrial chemicals (Pitschmann 2014), as is the case for phosgene and analogues. Maybe the best example for dual use of toxic chemicals represents chemical mustards; clinical findings of victims of a mustard release in Bari, Italy, in WWII, supported the discovery that mustards exert strong cytostatic effects on the hematopoietic system (DeVita and Chu 2008). This led to the dawn of modern cancer chemotherapy through the synthesis of several nitrogen mustards, yielding the first chemotherapeutic drug mustine (HN2, bis[2-chloroethyl]methylamine). In the following, several derivatives were developed, including chlorambucil, melphalan, and cyclophosphamide, all of which are still in clinical use to treat various forms of malignancies (DeVita and Chu 2008).

Toxicology discovers and researches adverse effects of chemical substances and thus can be considered as part of public health. There is therefore a high responsibility by individual scientists and by scientific institutions to identify potential for dual use of chemicals, especially to detect possibilities for abuse. Indeed, identification of dual use as a responsibility of all scientists has become an issue for grant-giving agencies, including the Deutsche Forschungsgemeinschaft by now. They have issued recommendations how scientists can and should be agents of responsible research. ${ }^{2}$

In conclusion, 100 years after the beginning of the First World War significant achievements to ban CWA were made. Yet, the threat that such agents will be used in the future is not averted. For this reason, every possible effort should be made to prevent the uncontrolled generation and distribution of chemicals as weapons. This is the realm of law, politics, and civil society. Besides this, research can prepare against the adverse effects of chemical weapons, including therapy, disaster management, and forensic verification.

\section{References}

Black RM (2010) History and perspectives of bioanalytical methods for chemical warfare agent detection. J Chromatogr B Analyt Technol Biomed Life Sci 878(17-18):1207-1215. doi:10.1016/j.jchromb.2009.11.025

DeVita VT Jr, Chu E (2008) A history of cancer chemotherapy. Cancer Res 68(21):8643-8653. doi:10.1158/0008-5472.CAN-07-6611

Dolgin E (2013) Syrian gas attack reinforces need for better anti-sarin drugs. Nat Med 19(10):1194-1195. doi:10.1038/nm1013-1194

Enserink M (2013) Chemical weapons. U.N. taps special labs to investigate Syrian attack. Science 341(6150):1050-1051. doi:10.1126/science.341.6150.1050

Fitzgerald GJ (2008) Chemical warfare and medical response during World War I. Am J Public Health 98(4):611-625. doi:10.2105/A JPH.2007.11930

Gupta [Ed] R (2009) Handbook of toxicology of chemical warfare agents. Academic Press

Kehe K, Balszuweit F, Steinritz D, Thiermann H (2009) Molecular toxicology of sulfur mustard-induced cutaneous inflammation and blistering. Toxicology 263(1):12-19. doi:10.1016/j.tox.2009.01.019

\footnotetext{
${ }^{2}$ http://www.leopoldina.org/uploads/tx_leopublication/2014_06 _DFG_Leopoldina_Wissenschaftsfreiheit_-verantwortung_D.pdf (Accessed 3.9.2014).
} 
Maurer H (2007) Analytical toxicology. Anal Bioanal Chem 388(7):1311. doi:10.1007/s00216-007-1387-8

Pitschmann V (2014) Overall view of chemical and biochemical weapons. Toxins 6(6):1761-1784. doi:10.3390/toxins6061761

Riches JR, Read RW, Black RM, Cooper NJ, Timperley CM (2012) Analysis of clothing and urine from Moscow theatre siege casualties reveals carfentanil and remifentanil use. J Anal Toxicol 36(9):647-656. doi:10.1093/jat/bks078

Rodgers GC Jr, Condurache CT (2010) Antidotes and treatments for chemical warfare/terrorism agents: an evidence-based review. Clin Pharmacol Ther 88(3):318-327. doi:10.1038/clpt.2010.152
Sydnes LK (2013) Policy: Update the Chemical Weapons Convention. Nature 496(7443):25-26. doi:10.1038/496025a

Szinicz L (2005) History of chemical and biological warfare agents. Toxicology 214(3):167-181. doi:10.1016/j.tox.2005.06.011

Thiermann H, Worek F, Kehe K (2013) Limitations and challenges in treatment of acute chemical warfare agent poisoning. Chem Biol Interact 206(3):435-443. doi:10.1016/j.cbi.2013.09.015

Yanagisawa N, Morita H, Nakajima T (2006) Sarin experiences in Japan: acute toxicity and long-term effects. J Neurol Sci 249(1):76-85. doi:10.1016/j.jns.2006.06.007 